\title{
An X-ray Diffraction Study of Silver Iodide from Aerosol Generators and a Preliminary Experiment on Ice-nucleating Ability of $\beta$-AgI and $\gamma$-AgI*
}

\author{
By A. Ono** and R. Kimura \\ Geophysical Institute, Tokyo University, Tokyo \\ (Manuscript received 17 October 1966, in revised form 1 February 1967)
}

\begin{abstract}
The crystal structure of silver iodide produced by an aerosol generator was studied with the aid of an X-ray diffractometer. The aerosols produced by the vaporization of a mixture of silver iodide and potassium iodide consisted of the hexagonal silver iodide $(\beta-\mathrm{AgI})$ and some complex, such as $\mathrm{KAg}_{3} \mathrm{I}_{4}$. Little trace of potassium iodide was detected in the aerosols. The aerosols produced by the vaporization of an iodide ion-rich silver iodide sample consisted mainly of the hexagonal form. On the other hand, the aerosols produced from a sample with an excess of silver ion consisted mainly of the low-temperature cubic form of silver iodide $(\gamma$-AgI) .

The low-temperature cubic form of silver iodide was found to be more efficient in icenucleating than the hexagonal form. The different efficiency could be explained in terms of the misfit of the crystal againt ice.
\end{abstract}

\section{Introductiton}

Silver iodide is one of the most effective icenucleating substances so far discovered. Its ice-nucleating properties were first discovered by B. Vonnegut in 1947, and since then it has been used extensively in cloud-seeding. Many papers have been written about the ice-nucleating ability of silver iodide aerosols and particular attention has been paid to the output rate of aerosol generators expressed as the number of ice nuclei active at various temperatures per gram of silver iodide. However, little is known about the crystal structure of the particles produced, which is surprising when one considers that Vonnegut originally chose silver iodide as a possible ice-nucleating substance because of its crystal structure.

Two forms of silver iodide are known. These are a low-temperature face-centred cubic zincblende structure $(\gamma-\mathrm{AgI})$ and a hexagonal wurtzite structure $(\beta-\mathrm{AgI})$. At $146^{\circ} \mathrm{C}$ these change reversibly to a body-centred cubic structure

* Division of Meteorology, Contribution No. 152.

** Present address: Radiophysics Laboratory, CSIRO, Sydney, Australia
$(\alpha$-AgI).

Relevant investigations have been reported by Manson (1955), who showed that when silver iodide was vaporized at several hundred degrees ${ }^{\circ} \mathrm{C}, \mathrm{X}$-ray diffraction patterns of silver iodide aerosols showed that they consisted of a mixture of the hexagonal and the low-temperature cubic forms with some indication that the hexagonal form became more dominant as the temperature of the source was increased.

Mason and Hallet (1956) have reported that electron diffraction patterns of silver iodide aerosols produced by the vaporization of a silver iodide and potassium iodide mixture showed little or no trace of either of the original compounds but suggested that mixed crystals were being formed. Electron diffraction patterns of silver iodide aerosols produced by the vaporization of silver iodide and sodium iodide revealed no trace of the hexagonal form of silver iodide $(\beta-A g I)$, but the patterns were consistent with those of either the low-temperature cubic form of silver iodide $(\gamma-\mathrm{AgI})$ or sodium iodide.

The physical causes for the predominance of one or the other have not been established by these experiments, and it is the aim here to 
attempt to fill this deficiency. Also, it has not been established whether the hexagonal form of silver iodide $(\beta$-AgI) or the low-temperature cubic form of silver iodide $(\gamma$-AgI) provides the more efficient ice nucleus, and this is the second point we have studied.

\section{Crystal structure of silve iodide aerosols produced from various kinds of genera- tors.}

\section{(a) Experimental}

(i) Source of silver iodide aerosols

Two types of silver iodide generators were studied: one burns a solution prepared by dissolving silver iodide and potassium iodide in acetone, and this type has been adopted for large-scale cloud-seeding; the other is an electric-heating-type generator which vaporizes pure silver iodide, but because of the amount of heat required and relatively small output rate it has not been adopted for large-scale cloud-seeding. This electric-heating-type generator is also used to vaporize a $3: 1$ mixture of silver iodide and potassium iodide, in addition to pure silver iodide. Silver iodide aerosols were sampled at the outlet of each generator by use of millipore filter ( 1.2 micron pore size).

(ii) X-ray diffraction patterns of silver iodide aerosols

The X-ray diffraction patterns of silver iodide aerosols were obtained using an X-ray diffractometer (Geigerflex). Experimental conditions were as follows: a copper anode tube excited at $35 \mathrm{Kvp}$ and $15 \mathrm{~mA}$ full wave rectified with $0.025 \mathrm{~mm} \mathrm{Ni}$ filter was used as a source of radiation; scanning speed was $1^{\circ}$

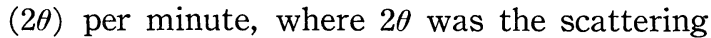

Table 1. The NBS standard X-ray diffraction powder patterns.

\begin{tabular}{l|r|r|r|r|r}
\hline \multicolumn{3}{c|}{$\begin{array}{c}\text { The hexagonal form of } \\
\text { silver iodide }(\beta-\text { AgI })\end{array}$} & \multicolumn{3}{|c}{$\begin{array}{c}\text { The low-temperature } \\
\text { cubic form of } \\
\text { iodide }(\gamma-\mathrm{AgI})\end{array}$} \\
\hline $\mathrm{d}(\mathrm{A})$ & $\mathrm{I} / \mathrm{I}_{0}$ & $(\mathrm{hkl})$ & $\mathrm{d}(\mathrm{A})$ & $\mathrm{I} / \mathrm{I}_{0}$ & $(\mathrm{hkl})$ \\
3.98 & 60 & 100 & & & \\
3.75 & 100 & 002 & 3.75 & 100 & 111 \\
3.51 & 40 & 101 & & & \\
2.731 & 16 & 102 & & & \\
2.296 & 85 & 110 & 2.30 & 58 & 220 \\
2.119 & 30 & 103 & & & \\
1.959 & 50 & 112 & 1.950 & 31 & 311 \\
\hline
\end{tabular}

angle; time constant was 4 seconds; divergent slit and receiving slit were $1^{\circ}, 0.2 \mathrm{~mm}$. For the determination of the crystal structure of silver iodide we compared the X-ray diffraction patterns observed with those of the standard one cited on the ASTM cards. The NBS stanndard X-ray diffraction powder patterns for the two forms of silver iodide are shown in Table 1.

It can be seen by the additional reflection lines that the hexagonal form of silver iodide $(\beta-\mathrm{AgI})$ is readily distinguished from the lowtemperature cubic form of silver iodide $(\gamma-\mathrm{AgI})$.

(b) Results

(i) Silver iodide aerosols produced by the vaporization of silver iodide in the electric-heating generator

The diffraction patterns for silver iodide aerosols produced by the vaporization of pure silver iodide at $960-1000^{\circ} \mathrm{C}$ are presented in Fig. 1. The lines observed are in close agreement with those expected from the standard hexagonal form of silver iodide $(\beta-\mathrm{AgI})$ of Table 1. Thus it is clear that the hexagonal form of silver iodide is present. However, the lowtemperature cubic form of silver iodide $(\gamma-\mathrm{AgI})$, as shown in Table 1 , has the reflection lines coinciding with those of the hexagonal form, so the low-temperature cubic form of silver iodide may be present. The exact proportions

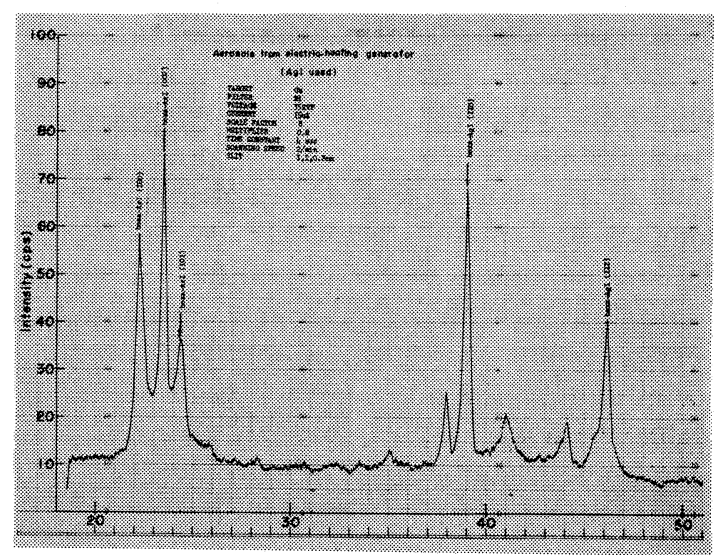

Fig. 1. The X-ray diffraction patterns for silver iodide aerosols produced by the vaporization of pure, solid silver iodide at $960-1000^{\circ} \mathrm{C}$ in the electric-heating generator. The abscissa expresses the scattering angle and the ordinate expresses the intensity of reflection in the unit of counts per sec. The figures at each reflection-line express the Muller index of silver iodide crystals. 
when both forms are present are hard to be determined.

Under ordinary conditions we always observed the diffraction patterns of silver iodide aerosols as presented in Fig. 1, but sometimes, usually in the final stage of vaporization, we observed another kind of diffraction pattern, as shown in Fig. 2. The diffraction patterns in Fig. 2 were obtained from the silver iodide aerosols produced by the vaporization of silver iodide at $960-1000^{\circ} \mathrm{C}$. The diffraction patterns of this sample agree completely with those of the low-temperature cubic form of silver iodide. In order to find out more about the conditions under which the low-temperature cubic form of silver iodide is obtained, we carried out another kind of experiment, as we shall discuss at Section (C).

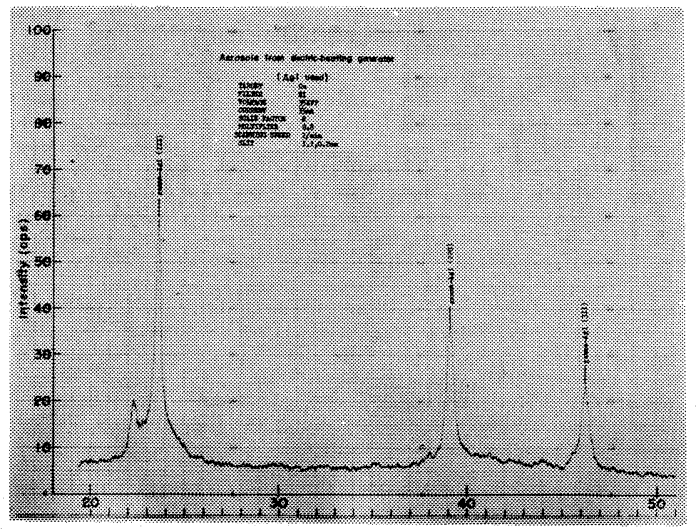

Fig. 2. The X-ray diffraction patterns for silver iodide aerosols produced in the final stage of vaporization of silver iodide at $960-1000^{\circ} \mathrm{C}$ in the electric-heating generator.

(ii) Silver iodide aerosols produced by the vaporization of silver iodide and potassium iodide in the electric-heating generator

The diffraction patterns obtained from the silver iodide aerosols produced by the vaporization of silver iodide and potassium iodide at $960-1000^{\circ} \mathrm{C}$ are presented in Fig. 3. The diffraction pattern is more complicated than the first two (see Fig. 1, Fig. 2), but we can easily distinguish the main characteristic diffraction pattern of the hexagonal crystalline form of silver iodide. The diffraction pattern produced by potassium iodide is very weak, because of the poor scattering power of the potassium atom compared to the strong scat- tering power of the silver atom. We infer from Fig. 3, therefore, that well-defined hexagonal crystalline silver iodide is being formed. The diffraction patterns show little trace of potassium iodide and suggest that some complex is being formed.

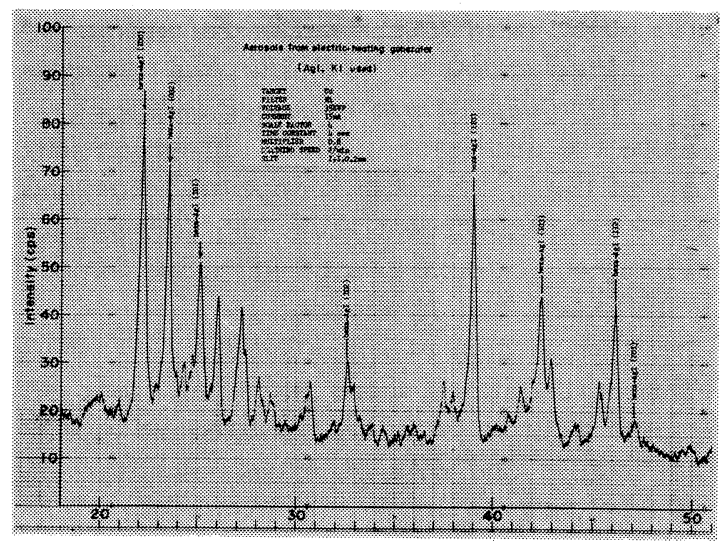

Fig. 3. The X-ray diffraction patterns for silver iodide aerosols produced by the vaporization of a mixture of pure, solid silver iodide and potassium iodide at $960-1000^{\circ} \mathrm{C}$ in the electric-heating generator.

(iii) Silver iodide aerosols produced by solution of silver iodide and potassium iodide in acetone

The diffraction pattern obtained from a solution burner is presented in Fig. 4. The diffraction patterns shown in Fig. 4 are very similar to those shown in Fig. 3. Here we can easily distinguish the main characteristic patterns of the hexagonal form of silver iodide but not

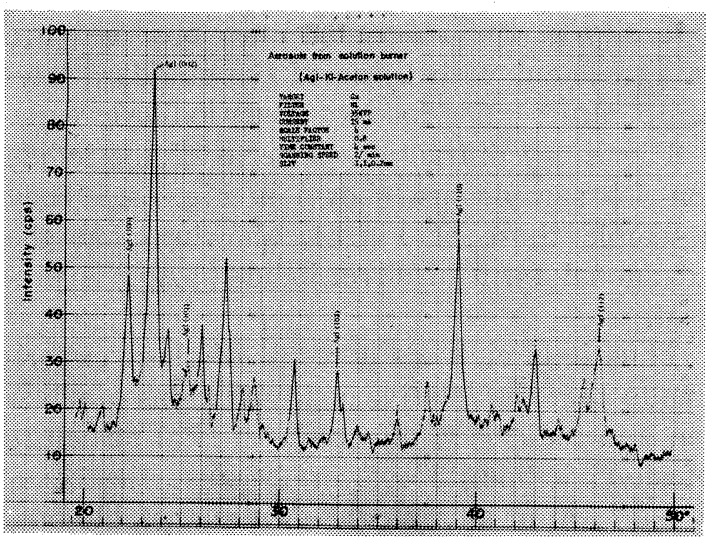

Fig. 4. The X-ray diffraction patterns for silver iodide aerosols produced by burning a solution of silver iodide and potassium iodide in acetone. 
of the patterns of potassium iodide. The reflection lines which we cannot identify are also very similar in the lattice-spacing to those shown in Fig. 3, suggesting that (according to the phase diagram of silver iodide-potassium iodide by Burley and Kissinger (1960), some complex like $\mathrm{KAg}_{3} \mathrm{I}_{4}$ is being formed.

(c) The condition for the formation of the hexagonal and the low-temperature cubic form of silver iodide

Since the difference between diffraction patterns in Fig. 1 and Fig. 2 appears to depend on the relative concentration of silver and iodine vapor, we next carried out some experiments to test this hypothesis.

(i) Preparation of silver iodide.

Two precipitates were prepared from an aqueous solution of silver nitrate and potassium iodide; one with an excess of silver ion and one with an excess of iodide ion. The first used a $0.5 \mathrm{M}$ potassium iodide solution added to $1 \mathrm{M}$ silver nitrate solution; the second used a $1 \mathrm{M}$ potassium iodide solution added to $0.5 \mathrm{M}$ silver nitrate solution.

The X-ray diffraction patterns of the two types of silver iodide were obtained with the aid of an X-ray diffractometer under the same conditions as described in 2 (b).

(ii) X-ray diffraction patterns for silver iodide precipitated from an aqueous solution

The X-ray diffraction patterns of the precipitate with an excess of silver ion are shown in Fig. 5. They are seen to be very similar to those in Fig. 2, indicating that the lowtemperature cubic form of silver iodide is being formed. The face distance and the relative intensity of the reflection lines observed are in agreement with those of the standard lowtemperature cubic form of silver iodide $(\gamma-\mathrm{AgI})$.

The X-ray diffraction patterns of the iodide ion-rich sample are shown in Fig. 6a. They resemble those of Fig. 1, showing that the hexagonal form of silver iodide $(\beta$-AgI) is present.

Thus it is clear as a result of these experiments that the relative concentrations of silver ion and iodide ion affect the crystal structure of silver iodide. However, because the hexagonal form of silver iodide is a metastable one, it was necessary to take certain precautions to obtain the X-ray diffraction patterns.

At first, in order to make uniform fine par-

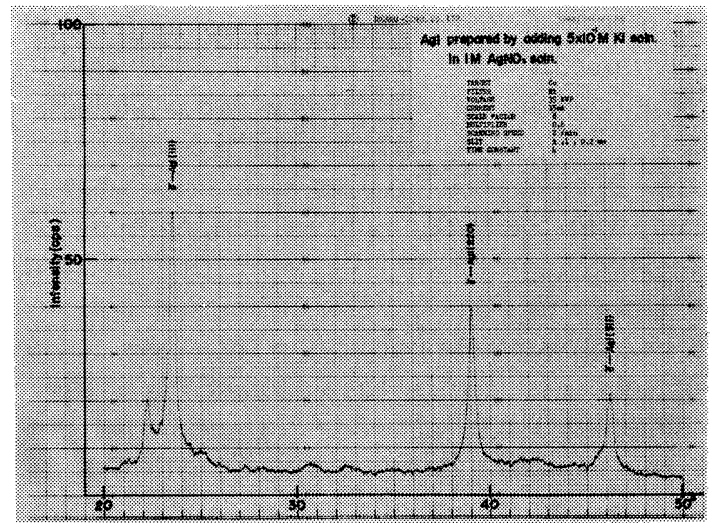

Fig. 5. The X-ray diffraction patterns for silver iodide precipitated from solution with an excess of silver ion.

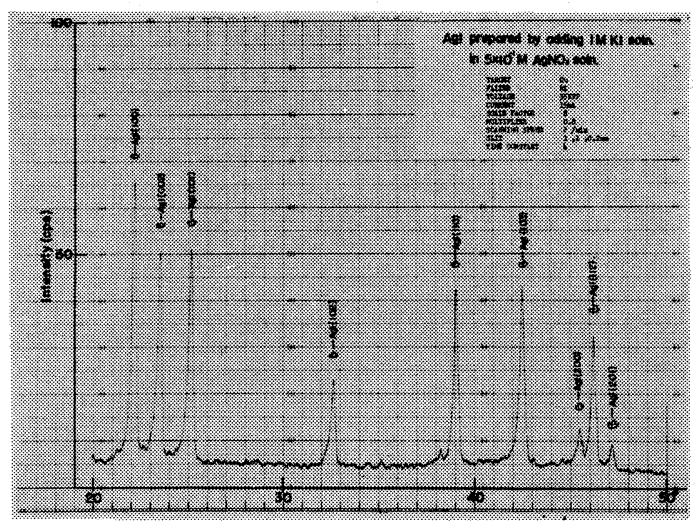

Fig. 6(a). The X-ray diffraction patterns for silver iodide precipitated from solution with an excess of iodide ion.

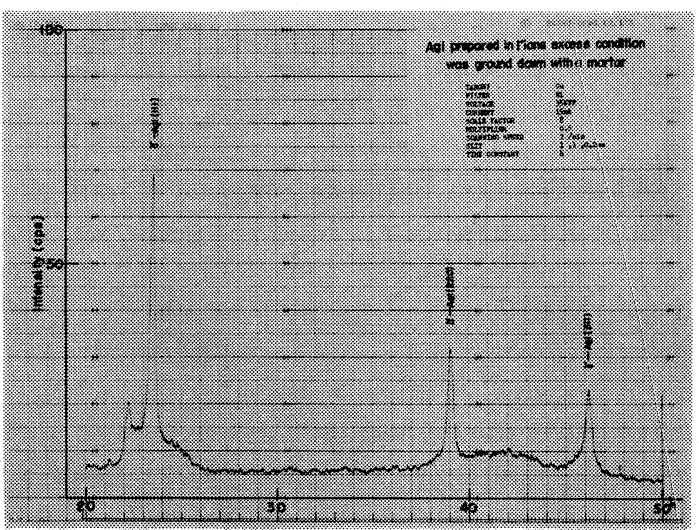

Fig. 6(b). The X-ray diffraction patterns for ground silver iodide precipitated from solution with an excess of iodide ion. 
ticles of silver iodide, which are necessary to obtain more accurate diffraction patterns, we ground silver iodide precipitate. The diffraction patterns of ground silver iodide showed the low-temperature cubic form of silver iodide $(\gamma$-AgI) (see Fig. 6b). It was found, after many trials, that grinding the hexagonal form of silver iodide converted it easily into the low-temperature cubic form of silver iodide. The diffraction patterns in Fig. 6a were obtained without grinding. The face distance observed is in agreement with that of the standard but the relative intensity of reflection lines observed is not in agreement (see Table 1). This disagreement in relative intensity may be due to non-uniform particle size.

As for silver iodide prepared from the complex solution formed by dissolving silver iodide in a strong aqueous solution of potassium iodide and diluting with pure water, the diffraction pattern obtained indicated the hexagonal form of silver iodide $(\beta-\mathrm{AgI})$. This is an expected result, because silver iodide from this complex solution is formed in an excess of iodide ion.

Although the result obtained here is not directly applicable to crystallization of silver iodide from vapor state, it seems to be likely that similar behaviour is found.

\section{Ice-nucleating ability of the hexagonal form and the low-temperature cubic form of silver iodide}

As mentioned above, it is clear that the method of preparation of silver iodide affected the crystal structure, for we were able to obtain both types of low temperature modification of silver iodide ( $\beta$-AgI, $\gamma$-AgI) under controlled conditions. Our next step was to compare the ice-nucleating ability of the hexagonal form of silver iodide ( $\beta$-AgI) and the low-temperature cubic form of silver iodide $(\gamma-\mathrm{AgI})$. Whether the hexagonal or the low-temperature cubic form of silver iodide provides the more efficient ice nuclei has not yet been established.

\section{(a) Experimental}

For these investigations an apparatus (similar to that of Brewer and Palmer [1951]) was used which enabled us to observe a water drop containing silver iodide particles while it is repeatedly frozen and thawed. Following is the process used.
A drop of distilled water of $0.05 \mathrm{ml}$ placed on a thin teflon plate $(1 \mathrm{~cm} \times 1 \mathrm{~cm} \times 0.5 \mathrm{~mm})$ is supercooled in a temperature gradient cold chamber, in which the temperature at the top is above $0^{\circ} \mathrm{C}$ and at the bottom $-18^{\circ} \mathrm{C}$. The water drop is carried slowly into the cooler part of the chamber, the speed of descent corresponding to a cooling rate of $1^{\circ} \mathrm{C} / \mathrm{min}$. The freezing of a water drop is accompanied by a sudden increase in temperature, owing to release of latent heat, and we can detect the moment of freezing from the rapid change of temperature. At the same time this rapid change of temperature acts as a pulse, and a controller circuit changes the state of the mechanical system so that the sample is rapidly carried back into the initial state where the temperature of ambient air is above $0^{\circ} \mathrm{C}$. After a certain time when the sample has melted again it starts descending at the cooling rate of $1^{\circ} \mathrm{C} / \mathrm{min}$ into the colder part of the chamber. The process is repeated automatically. The temperature of the sample is measured by a thermocouple which is placed on the underside of the teflon plate, and is recorded continuously by a strip chart recorder.

In general, it is not advisable to use water drops as large as we used in the present experiment if a correspondence to the phenomena in natural clouds is required. However, to compare the ice-nucleating ability of ice nuclei, especially when their properties are (like the hexagonal and the low-temperature cubic forms of silver iodide) very similar, a large water drop is more suitable because of the small effect of the volume variation of the sample on its freezing-temprerature.

The direct value of temperature obtained by the thermocouple is the average of the temperature of the underside of the teflon plate and of the ambient air. The temperature of the sample in the cooling stage is always about $1^{\circ} \mathrm{C}$ warmer than the ambient air because of the heat capacity of the sample. So the absolute value of temperature cannot be measured to better than $\pm 1^{\circ} \mathrm{C}$, but we can detect differences of freezing-temperature to about $\pm 0.1^{\circ} \mathrm{C}$

Firstly we measured the freezing-temperature of distilled water as a background to these experiments. We obtained freezing-temperatures with 10 samples, each of which was 


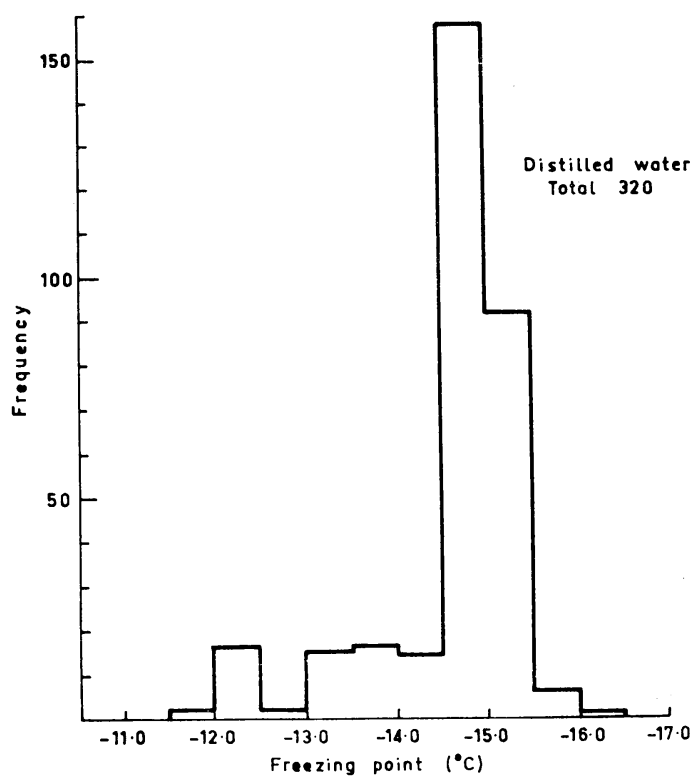

Table 2. The freezing temperature of distilled water.

Fig. 7. The histogram of the freezing-temperature of distilled water.

\begin{tabular}{c|c|c}
\hline Sample No. & $\begin{array}{c}\text { Freezing tempera- } \\
\text { ture }\left({ }^{\circ} \mathrm{C}\right)\end{array}$ & $\begin{array}{c}\text { Standard deviation } \\
\left({ }^{\circ} \mathrm{C}\right)\end{array}$ \\
\hline 1 & -14.7 & 0.30 \\
2 & -12.2 & 0.21 \\
3 & -13.9 & 0.49 \\
4 & -14.7 & 0.29 \\
5 & -15.0 & 0.23 \\
6 & -15.3 & 0.40 \\
7 & -14.8 & 0.26 \\
8 & -14.8 & 0.15 \\
9 & -15.0 & 0.25 \\
10 & -15.1 & 0.23 \\
\hline Average & -14.6 & 0.3 \\
\hline
\end{tabular}

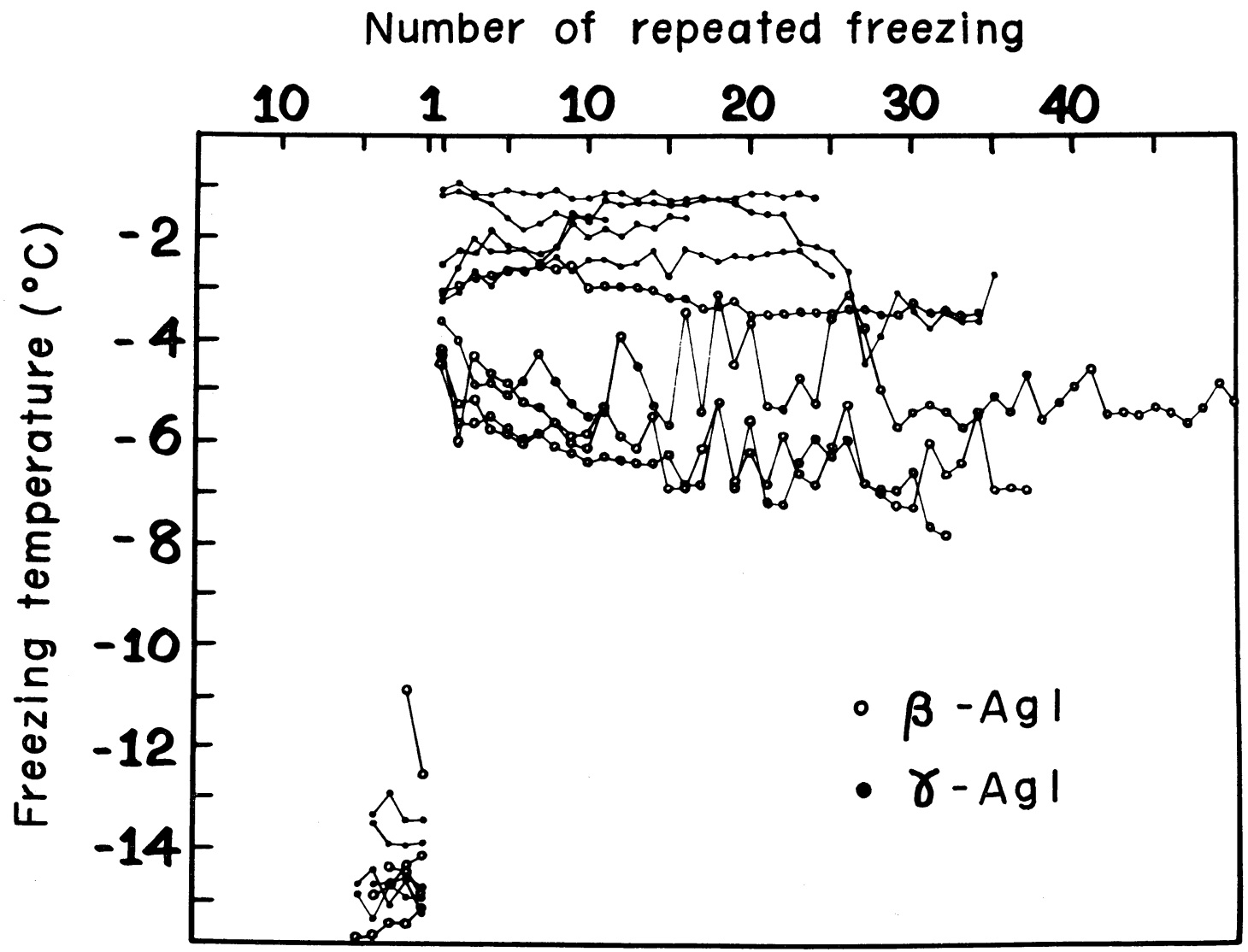

Fig. 8. The freezing-temperature of distilled water containing silver iodide particles. 
repeatedly frozen and thawed from 10 to 66 times. The freezing-temperature of distilled water obtained with the use of this apparatus is shown in Fig. 7 and Table 2. The average freezing-temperature was $-14.6 \pm 0.3^{\circ} \mathrm{C}$. As shown in Fig. 7 and Table 2 the freezing-temperature of distilled water is fairly constant with small deviations. Hence it is very easy to detect the ability of an ice nucleus substance if the sample freezes at a temperature warmer than $-10^{\circ} \mathrm{C}$ and to say that the crystallization must be caused by the ice-nucleating substance introduced into the sample.

(b) The freezing-temperature of distilled water containing silver iodide particles

We observed the freezing-temperature of 10 samples of distilled water, half of which contained the hexagonal form of silver iodide $(\beta$ AgI) and the rest of which contained the lowtemperature cubic form of silver iodide $(\gamma-\mathrm{AgI})$. Silver iodide used in this experiment was obtained by the vaporization of silver iodide, and their crystal structure was identified from the $\mathrm{X}$-ray diffraction patterns as mentioned in the section 2.

The freezing-temperature of distilled water containing silver iodide particles is shown in Fig. 8. The first few cycles of freezing and thawing were used as a check of background - that is, we observed the freezing-temperature of distilled water and then introduced silver iodide particles into the same sample and observed the change of freezing-temperature. The amount of silver iodide was not specially measured, but so much was introduced that it was deposited on the bottom of the water drop. According to the results by Edwards et al. (1962), the larger the size of silver iodide particles the more effective they are. Therefore, in our present experimental condition, the ice-nucleating ability of silver iodide seems to show the maximum nucleating ability. The histogram of the freezing-temperatures of distilled water containing the hexagonal form $(\beta$-AgI) and the low-temperature cubic form of silver iodide $(\gamma$-AgI) is shown in Fig. 9. The mean temperature and the standard deviation of each sample are shown in Table 3. Though the standard deviation of freezingtemperature of each sample is larger than that of distilled water, there is a clear tendency that samples containing the low-temperature cubic form of silver iodide $(\gamma-A g I)$ freeze at a higher temperature than those containing the

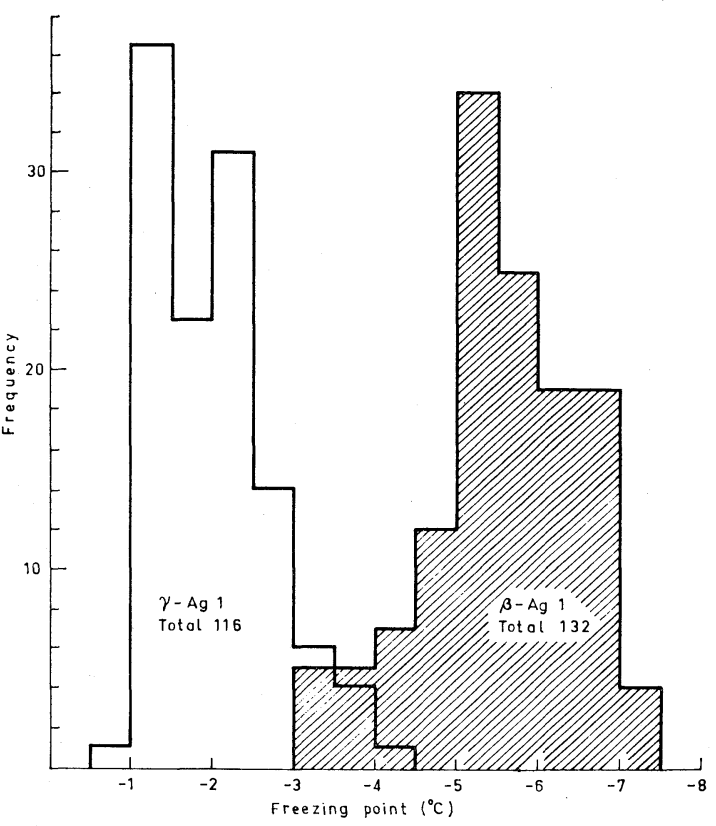

Fig. 9. The histogram of the freezing-temperature of distilled water containing the low-temperature cubic form of silver iodide $(\gamma$-AgI) and the hexagonal form of silver iodide $(\beta-\mathrm{AgI})$.

Table 3. The freezing temperature of distilled water containing $\gamma$-AgI and $\beta$-AgI particles.

(a) $\gamma$-AgI

\begin{tabular}{c|c|c|c}
\hline $\begin{array}{c}\text { Sample } \\
\text { No. }\end{array}$ & $\begin{array}{c}\text { Number of } \\
\text { freezing }\end{array}$ & $\begin{array}{c}\text { Mean freezing } \\
\text { Temperature } \\
\left(\mathbf{C}^{\circ}\right)\end{array}$ & $\begin{array}{c}\text { Standard De- } \\
\text { viation }\left({ }^{\circ} \mathrm{C}\right)\end{array}$ \\
\hline 1 & 35 & -2.2 & 0.90 \\
2 & 11 & -1.4 & 0.23 \\
3 & 30 & -2.4 & 0.31 \\
4 & 24 & -1.1 & 0.07 \\
5 & 16 & -2.1 & 0.40 \\
\hline Average & & -1.8 & 0.4 \\
\hline
\end{tabular}

(b) $\beta$-AgI

\begin{tabular}{c|c|c|c}
\hline $\begin{array}{c}\text { Sample } \\
\text { No. }\end{array}$ & $\begin{array}{c}\text { Number of } \\
\text { freezing }\end{array}$ & $\begin{array}{c}\text { Mean freezing } \\
\text { Temperature } \\
\left({ }^{\circ} \mathrm{C}\right)\end{array}$ & $\begin{array}{c}\text { Standard De- } \\
\text { viation }\left({ }^{\circ} \mathrm{C}\right)\end{array}$ \\
\hline 1 & 34 & -3.1 & 0.32 \\
2 & 32 & -6.1 & 0.73 \\
3 & 12 & -5.6 & 0.49 \\
4 & 50 & -4.9 & 0.68 \\
5 & 37 & -6.0 & 0.81 \\
\hline Average & & -5.1 & 0.6 \\
\hline
\end{tabular}


hexagonal form of silver iodide ( $\beta$-AgI). The mean freezing-temperature of the low-temperature cubic form of silver iodide $(\gamma-\mathrm{AgI})$ is -1.8 $\pm 0.4^{\circ} \mathrm{C}$, and the mean freezing-temperature of the hexagonal form $(\beta-\mathrm{AgI})$ is $-5.1 \pm 0.6^{\circ} \mathrm{C}$. The scatter of freezing-temperature in one sample is thought to be attributable to the fact that there are various kinds of active sites with different nucleating ability on silver iodide which may be altered by the freezing process. It may be concluded as a result of this experiment that the ice-nucleating ability of the lowtemperature cubic form and the hexagonal form of silver iodide are different, and that the low-temperature cubic form of silver iodide is more efficient than the hexagonal form.

\section{Discussion}

Since silver iodide decomposes on heating and since the silver is less volatile than the iodine, the crystal structure obtained from generators of silver iodide will depend on the burner design. As we have shown, the crystal structure appears to affect ice-nucleating performance and this may have practical importance.

Another consequence of our results is that an alternative explanation of Edwards and Evans experiments is suggested. The difference of ice-nucleating ability between the low-temperature cubic form of silver iodide and the hexagonal form of silver iodide may well explain the difference of the freezing-temperature of sol A and sol B in pure water which Edwards and Evans (1962) obtained in their study of the effect of surface charge in ice-nucleation on silver iodide. They observed that sol A particles prepared from a solution with an excess of indide ion nucleated pure water at $-18^{\circ} \mathrm{C}$, while sol $\mathrm{B}$ particles from a solution with an excess of silver ion nucleated pure water at $-9^{\circ} \mathrm{C}$, (see their Fig. 1 and Fig. 2). Based on the effect of surface charge in nucleation, they carried out zeta-potential measurements in the expectation that the charge in pure water of the inactive sol A would be strongly negative, while that of active sol B particles would be near zero. But no difference was observed, and all particles exhibited negative zeta-potential in pure water as high as $-50 \pm 15 \mathrm{mV}$. Considering their method of preparation of silver iodide, we may conclude that sol A par- ticles prepared from a solution with an excess of iodide ion consisted of the hexagonal form of silver iodide ( $\beta$-AgI) and sol B particles prepared from solution with an excess of silver ion consisted of the low-temperature cubic form of silver iodide $(\gamma-\mathrm{AgI})$. So if we take into consideration the difference of crystal structure between sol A and sol B, the tendency for sol $B$ to provide more efficient ice nuclei than sol A is in agreement with the result of our present experiments.

The difference of ice-nucleating ability of the low-temperature cubic form of silver iodide $(\gamma-\mathrm{AgI})$ and the hexagonal form of silver iodide $(\beta$-AgI) may well be explained by the theory proposed by Fletcher (1959). Fletcher had shown that owing to the effect of bond orientation in ice the ideal nucleating surface should have a zero net charge. As a result, he concluded that the basal face of the hexagonal form of silver iodide, being composed of one type of atom only, would act as a poor nucleating surface, and that the activity of the hexagonal form of silver iodide would be mostly confined to the prism face which is composed of an equal number of silver and iodide atoms. Following his reasoning, we assume that the ideal nucleating surface should have a zero net charge. The crystal face of the low-temperature cubic form of silver iodide which satisfies the above mentioned assumption is the diagonal face (111), and this face is geometrically identical to the basal face of the hexagonal form of silver iodide. The low-temperature cubic form of silver iodide has a diagonal misfit against ice of $1.4 \%$, and the hexagonal form of silver iodide has a prism misfit of $1.6 \%$ (see Table 4 ).

Table 4. The misfit for $\gamma$-AgI and $\beta$-AgI

\begin{tabular}{c|c|c}
\hline Substance & Crystal face & Misfit (\%) \\
\hline$\gamma$-AgI & $(111)$ & 1.4 \\
$\beta$-AgI & $(100)$ & 1.6 \\
& $(001)$ & 1.4 \\
\hline
\end{tabular}

Then, from the point of view of the misfit against ice, the low-temperature cubic form of silver iodide provides more efficient ice nucleus than that of the hexagonal from of silver iodide. We do not know at present whether the diagonal face of the low-temperature cubic form of silver iodide is usually a well-exposed 
one or not, but if we make the assumption mentioned above we can explain the difference in the ice-nucleating ability of the low-temperature cubic form of silver iodide and the hexagonal form of silver iodide. Though the results of our nucleation experiments can be satisfactorily explained in terms of the crystal structure of silver iodide, we must not overlook the possible influence of soluble impurities. To check this influence it is necessary to observe the ice-nucleating ability of $\beta$-and $\gamma$-AgI for ice crystal growth by sublimation.

\section{Acknowledgments}

The authors would like to express their deep thanks to Professor S. Syōno for his kind encouragement and discussions throughout the present work. The authors are particularly indebted to Professor K. Isono, Water Research Laboratory, Nagoya University, for his suggestions, critical discussions and kind encouragement throughout the present work. They also wish to express thanks to Professor R. Morimoto, Earthquake Research Institute, Tokyo University, who allowed them to use the X-ray diffractometer. Thanks are also due to Messrs. A. Yamashita and Y. Fujiki for their help in the experiments.

\section{References}

Brewer, A.W., and H.P. Palmer, 1951: Freezing of supercooled water. Proc. Phys. Soc., B64, 765773.

Burley, G., and H.E. Kissinger, 1960: Systems silver iodide-sodium iodide and silver iodide-potassium iodide. J.Res. N.B.S., A 64, 403-404.

Edwards, G.R., L.F. Evans, and V.K. LaMer, 1962: Ice nucleation by monodisperse silver iodide particles. J.Coll. Sci., 17, 749-758.

Edwards, G.R., and L.F. Evans 1962: Effect of surface charge on ice nucleation by silver iodide. Trans. Faraday Soc. 58, 1649-1655.

Fletcher, N.H., 1959: Entropy effect in ice crystal nucleation. J.chem. Phys., 30, 1476-1481.

Manson, J.E., 1955: X-ray diffraction study of silver iodide aerosols. J. appl. Phys.. 24, 423-425.

Mason, B.J., and J. Hallet, 1956: Artificial ice-forming nuclei. Nature, 177, 681-683.

Vonnegut, B., 1947: The nucleation of ice formation by silver iodide. J.appl. Phys., 18, 593595.

\title{
発煙炉より発生した沃化銀エエロゾルの $\mathrm{X}$ 線回析による結晶構造の研究 及び $\beta-\mathbf{A g I}$ と $\gamma-\mathbf{A g I}$ との水晶形成能力について
}

\author{
小野晃・木村竜治 \\ (東京大学理学部地球物理学教室)
}

初め飞発煙炬から発生した沃化銀エエロゾルの結晶構造を X 線回析装置で調べた。沃化銀一沃化加里を加熱蒸発 した場合飞は $\beta$ - AgI, 及び $\mathrm{KAg}_{3} \mathrm{I}_{4}$ 飞由来する回析図形が得られたが，沃化加里飞由来する回析図形は得られなかっ た。沃化銀だけを加熱蒸発する場合には, 一部が沃素と銀と分解し, 沃素の蒸気が過剩の時, $\beta$-AgI と $\gamma$-AgI 飞由 来する回折図形が得られた。一方, 銀の蒸気が過㮃の時, $\gamma$-AgI 飞由来する回析図形が得られた。

次飞, 発煙炬から得られた AgI とついてX線回析図形とよって結晶構造を同定した後, 水晶形成能力を測定し, $\gamma$-AgI を含む試料が $\beta$-AgI よりも効果が大きいという結果を得た。更飞両者の水晶形成能力の差とついて物理的な 解釈を試みた。 